\title{
Discovery in Statics
}

\author{
Sergey Makarov \\ Independent Researcher, Riga, Latvia \\ Email: segrim@bas.lv
}

Received September 3, 2013; revised October 1, 2013; accepted October 25, 2013

Copyright (C) 2013 Sergey Makarov. This is an open access article distributed under the Creative Commons Attribution License, which permits unrestricted use, distribution, and reproduction in any medium, provided the original work is properly cited.

\begin{abstract}
This article described the opening of a new law in fundamental physics, namely the law of the formation of an endless series of suspension (cable-stayed) networks coatings. Opening relates to the mechanics, section of statics.
\end{abstract}

Keywords: Cables; Cable-Stayed Network; Support Contour; Suspension Roof; Space; Space Hotel

\section{Introduction}

One of the branches of basic physics is mechanics. Mechanics is divided into statics, kinematics and dynamics. Statics is the section of mechanics that studies the equilibrium of solid, liquid or gaseous bodies at rest under the influence of external forces. We know that all construction projects are static objects, so the construction industry has long been the main consumer of scientific research statics. The needs of the construction, in their turn, stimulated the development of this science.

How much do we know of discoveries in statics? Probably not much. Apparently, the latest discovery, registered in the statics, is the "Law of Archimedes" about the force, which acts on a body immersed in a fluid.

I am a trained civil engineer. In 1977, after graduation from the institute instead of a diploma project, I have "excellent" defended my scientific research work. Around 1983 I began to research the development of suspension roofs (cable-stayed systems).

\section{The Emergence of Cable-Stayed Systems in Construction}

The first building, which was covered with a suspension roof was built in the Raley city (USA) in 1953. A general view of the building is shown in Figure 1.

After that, the building began construction of cablestayed roofs around the globe. As the carrier elements in the coating was first applied cable-stayed network, whereby the entire coating became about four times lighter than was previously possible. This building has convincingly shown a clear advantage of cable systems over all other coating systems. It was later built a lot of buildings that used cable system. However, each such building was a unique object. In the matter of creation of cable structures of roofs any explicit methodical system were no created.

\section{My Researches of Cable-Stayed Systems}

In the course of my research, I was able to create a number of new cable-stayed systems. The first four of these are shown in Figure 2.

My cable-stayed systems of coatings do not require any device side braces for the perception of effort from the cables. All internal efforts in structure are fully closed to itself and they are completely perceived by rigid support contour which can be made, for example, as a thin wavy closed rod. This fact turns out to be promising for application such structures in space and on the surfaces of other planets. In Figure 3 is shown one of the structures whose contour is made of thin copper pipe. This model is in my closet for over twenty years, but the tension force of its network virtually unchanged.

Waves of support contour do not necessarily have the same magnitude in the vertical direction. For the best possible removal of rainfall from the roof to the entire surface be better to give the overall slope. An example of such a cable-stayed system is shown in Figure 4.

Following the development of schemes of creation cable-stayed nets for the three, four, five, six (according to the number of waves on the support contour), I decided to patent them. As a result, I got the one-man's authors certificate for "suspension roof":

Inventor’s Certificate SU № 1270256 A1 (http://worldwide.espacenet.com/publicationDetails/mos aics $? \mathrm{CC}=\mathrm{SU} \& \mathrm{NR}=1270256 \mathrm{~A} 1 \& \mathrm{KC}=\mathrm{A} 1 \& \mathrm{FT}=\mathrm{D} \&$ date $=$ $19861115 \& \mathrm{DB}=\mathrm{EPODOC} \&$ locale $=$ en_EP) 


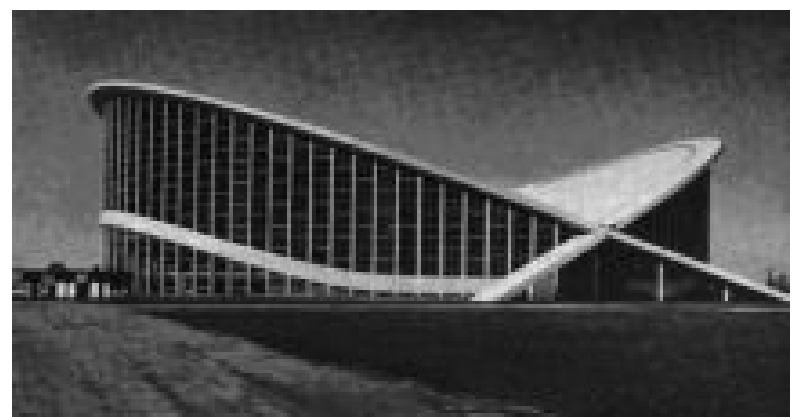

Figure 1. Raley arena.

(http://artyx.ru/books/item/f00/s00/z0000026/st026.shtml)

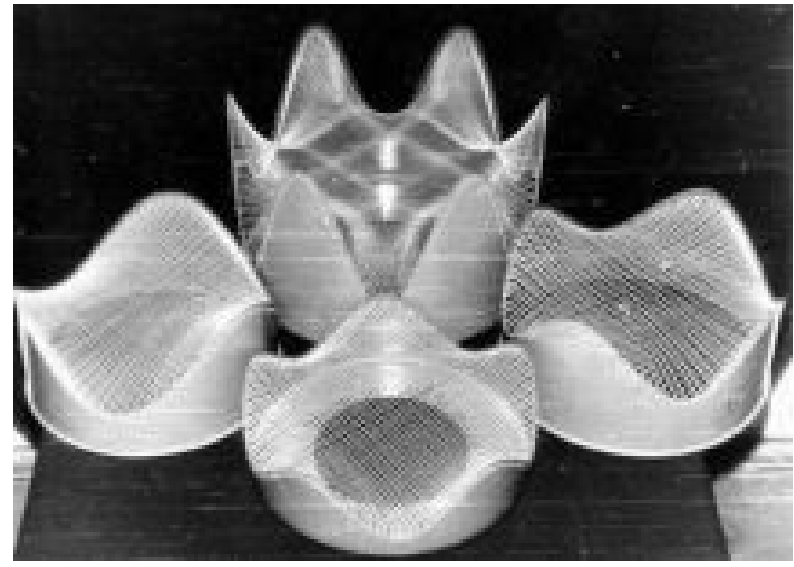

Figure 2. My first four models.

(http://hammer.bas.lv/ mid_10.htm\#X00)

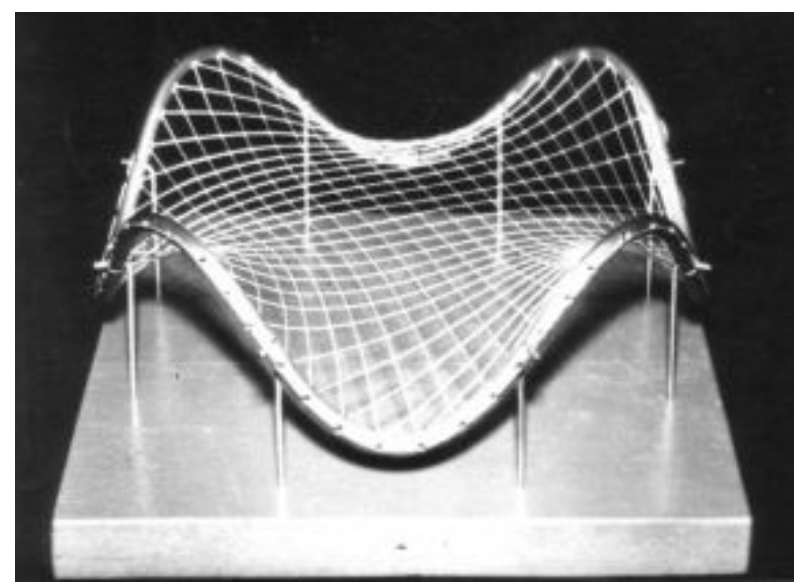

Figure 3. My “quartet”.

(http://hammer.bas.Iv/mid_10.htm\#X08)

Shown in scheme in the description of invention "sectors of unchanged cables orientation"- a central angles within which each of the cables is placed either strictly on the top of surface, or strictly on the bottom of surface. The more waves are made on the support contour, the less are these angles.

Next, I continued to develop the schemes of creation cable-stayed nets to contours with more number of waves.

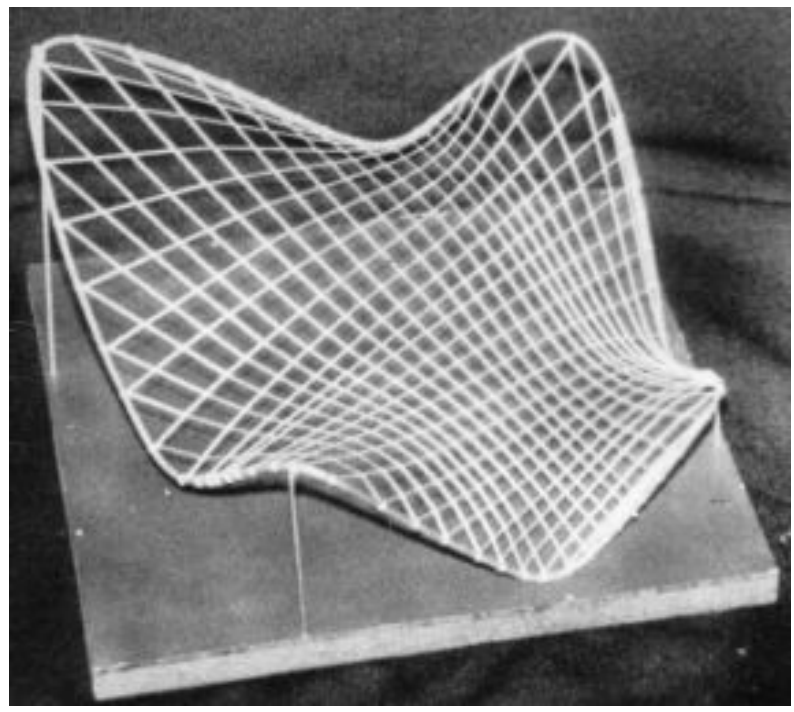

Figure 4. My “Gorb quartet”.

(http://commons.wikimedia.org/wiki/File:Quartet_gorb_1_3. jpg)

I have developed the network schemes for seven, eight and nine.

From the mathematics is known: for the discovering of the general formula for the sequence you must have at least three of its first members. If we consider the cable-stayed structures with an even number of waves on the contour, it will be four, six and eight. If you will analyze the coatings with an odd number of waves, it will be five, seven and nine.

The schemes of creation each of mentioned above cable-stayed nets I re-invented every time. When I created a number of networks to nine inclusive, I became able to detect and record the mathematical law of their formation. As a result, I got the ability to create the joint (i.e. without separations in all of the intersections of cables) cablestayed network with an arbitrary previously fixed number of contour waves of four to infinity. I wrote the discovered by me law of formation of such networks and registered it with the notary.

\section{The Law of Compatibility: Law of Compatibility of Quasi-Ortogonal Tangentially-Undulated Cable-Stayed Networks}

It is established the previously unknown regularity of existence of joint quasi-orthogonal strained networks, which are formed by two families of cables, which are focused along the geodesic lines of approximated with the help of network the tangential-undulating surface, which has a rotational symmetry of order " $n$ " (" $n$ "positive integer greater than or equal to four) consisting in the fact that, starting from the main zero line all the following each other in the tangential direction central 
angles, corresponding to sectors of unchanged orientation of cables relative to the approximated surface, within a complete revolution obey to the following sequences:

-if " $n$ " - an even integer and $n \geq 4$, then

$$
\underbrace{\frac{\pi}{n-2}, \frac{\pi}{n-2}, \cdots, \frac{\pi}{n-2}}_{2(n-2)}
$$

-if " $n$ " - an odd integer and $n \geq 5$, then

$$
\frac{3 \pi}{2 n}, \underbrace{\frac{\pi}{n}, \frac{\pi}{n}, \cdots, \frac{\pi}{n}}_{(n-5) / 2}, \frac{2 \pi}{n}, \underbrace{\frac{\pi}{n}, \frac{\pi}{n}, \frac{\pi}{n}, \cdots, \frac{\pi}{n}}_{(n-5) / 2}, \frac{3 \pi}{2 n}, \frac{3 \pi}{2 n}, \underbrace{\frac{\pi}{n}, \frac{\pi}{n}, \cdots, \frac{\pi}{n}}_{(n-5) / 2}, \frac{2 \pi}{n}, \underbrace{\frac{\pi}{n}, \frac{\pi}{n}, \frac{\pi}{n}, \cdots, \frac{\pi}{n}}_{(n-5) / 2}, \frac{3 \pi}{2 n}
$$

(Signature) MAKAROV S.G.

I, PASHALIS O.V., a notary public of the 3-d State notary office of the city of Leningrad, certify that on Sept 8,1989 in 12 hours and 45 minutes this document is presented to me in the aforesaid state notary's office by Makarov Sergey Grigorievich citizen residing at the address GATCHINA, Leningrad region, Gagarin street, house number 19, a hostel.

Man's personality, who gave the document, was identified.

Registered in the register № 3122-Д2

(The stamp of the Notary's Office) Recovered state fee 50 cents

\section{NOTARY PUBLIC: (Signature)}

Explanation: zero lines is contingent lines passing horizontally through the center of the coating. Throughout the whole length of such lines the heights of all points of coating are equal to zero (the vertical axe of the coordinate system is directed up). The main zero line is such line, from which in going counter-clockwise (when viewed from the top down) the heights of points of the support contour increases.

In Figure 5 I present a photocopy of the original document certified by a notary public (in Russian).

\section{Judgment of Specialists}

In the book [1] to the page. 32 you can read the following text: "However, creation a rational orthogonal cablestayed network on the support contour of three and more inclined to the horizont arches, using just two families of cables through the entire surface is not possible".

On the page 31 in the same book [1] it is written the following: "Justified... is seeking for new rational decisions for creation of cable networks, which would have all the advantages of hyperbolic-parabolic networks and will not contain hard elements, except the support contour".

Thus, in 1974 leading specialists declared all my shown above structures as "impossible structures". How could this happen? As far as I understand, the experts did not imagine that someone will begin create a cablestayed networks FROM CONVEX-CONCAVE cables. Until me all the suspension roofs were created from the cables, which had throughout whole their path of the same sign of curvature. One series of cables was regarded as the CARRIER series, another series of cables was considered to be STRESSER series. If you needed to create a cable-stayed network with several waves onsupport contour (more than two), then the series of "hypars" (this word is derived from two words "hyperbolic paraboloid") were simply blocking with each other with the help of some rigid details, which significantly worsened the quality of this coating and led to the increasing of its weight.

\section{Prospects of Application}

Cable-stayed networks of my structures do not lose consistency network after different affine deformations (compression, tension, shear), which makes them suitable for the construction of buildings, even on sloping surfaces.

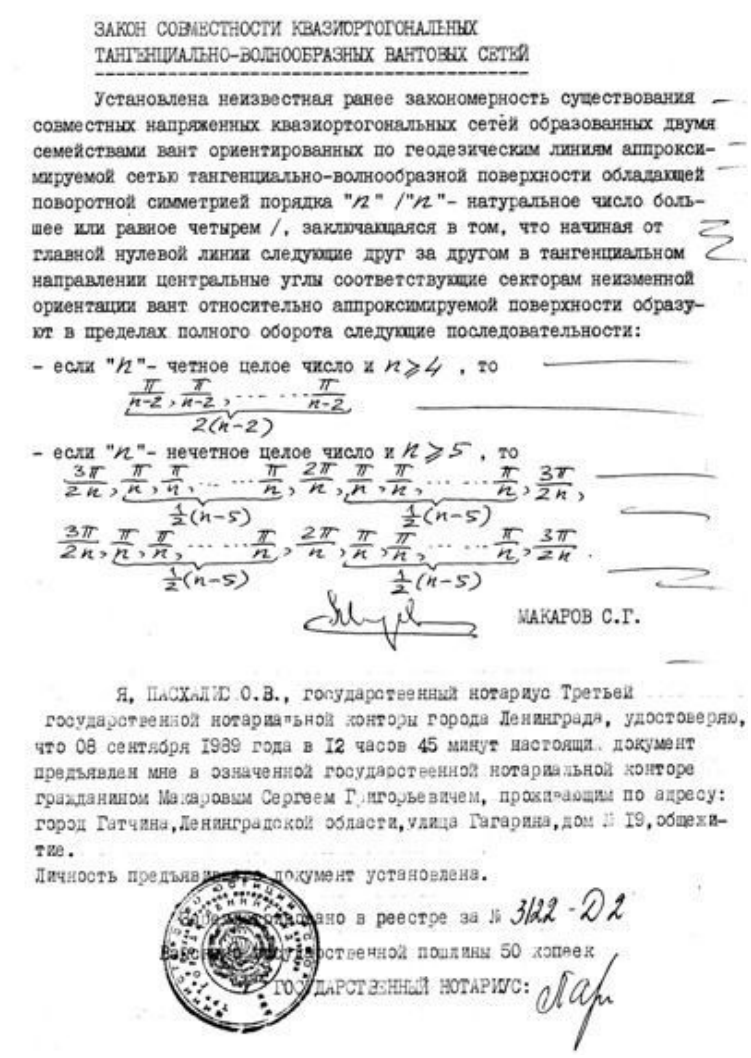

Figure 5. My law certified by a notary public. (http://hammer.bas.lv/cent_10.htm\#L02) 
Further on the basis of this law, I established a series of new designs, which are particularly suitable for the construction in space the "space towns" about which a hundred years ago wrote Tsiolkovsky. This series of designs you can see at the page "Space Architecture" (http://commons.wikimedia.org/w/index.php?title=Categ ory:Space_architecture) of British encyclopedia "Wikimedia Commons". Nowadays, one of the most urgent tasks in space exploration is the need to build space hotels. My solution to this problem is based on the application of the above law (look the presentation "Multi-Storey Space Hotel"

(http://www.slideshare.net/segrim/space-hotel-eng1)).

With the method, which is described in this presentation, can be built also the solar reflector with a diameter of several kilometers. Such reflector is required to change the trajectory of asteroid Apophis, which will arrive to our Earth April 13, 2029.

\section{Recent Comments}

The above law marked the beginning of an endless series of new cable-stayed structures. The history of architecture and building was not like this.

Is it possible that the law declared above be really recognized as DISCOVERY? For professional patent specialists, the main feature of discovery is the presence of the SERIES OF INVENTIONS that arise on the basis of opening. If such a series exists - opening exists. For comparison as an example, I can give the opening of the Niels Bohr of the quantum transitions of electrons from orbit to orbit. When the working body is pumping by the energy, the electrons are increasing their energy and they are moving to the upper levels of the electron orbits, fur- ther if under certain conditions the electrons are "falling" to lower orbits, they synchronously emit stored energy. All this was described by Niels Bohr in a small article about a hundred years ago. However, his discovery became the beginning of the "laser era". This discovery was followed by the inventions of a lot of lasers for a wide range of electromagnetic frequencies.

Previously, information about my discovery has been published in the press. See, for example, such sources: [2-6].

All of my cable-stayed networks are static rope constructions of mechanics. Until now, the latest discovery in mechanics, in "static" section, was registered by mankind for more than two thousand years ago.

\section{REFERENCES}

[1] L. G. Dmitriev and A. V. Kasilov, "Cable-Stayed Roof Systems," Budyvelnik, Kiev, 1974.

[2] S. Makarov, "Discovery in Mechanics," Techno-Community of Russia, 2013.

[3] S. Makarov, "Discovery in Mechanics," Agency Technical and Scientific Information, Scientific and Technical Library, 2013.

[4] S. Makarov, "Discovery in Mechanics," Techno-Community of Russia, 2013, in Russian.

[5] S. Makarov, "Discovery in Mechanics," Science Internet Portal "SCIENCEEDGE.NET", 2013, in Russian.

[6] S. Makarov, "Discovery in Mechanics," Agency Technical and Scientific Information, Scientific and Technical Library, 2013, in Russian. 